layer of unstriped muscle and a thick coat of inflamed fibrofatty tissue with extravasated blood in it.

The prostate (Fig, 3) is misshapen, the lateral lobes are merged into a projecting central lobe which overhangs the outlet of the bladder. A small glass rod $R$ is lying in the prostatic urethra. There can be little doubt that prostatic obstruction created the straining efforts which ended in the formation of the diverticulum. These diverticula are stated to possess no muscular wall of their own, but according to Tillmanns ${ }^{2}$ either all the layers of the bladder wall bulge out at some particular point or only the mucous membrane which has pushed its way through the muscular coat.

In the case related there was a thin muscular coat seen in the section of the cyst wall. According to Schmaus ${ }^{3}$ separation of the fibres of muscle allows the mucosa to protrade between them and thus "diverticula form. These occur with obstacles to the outflow and may be multiple." In my case in addition to the large sac there was in the right side of the bladder a foramen apparently opening into a second small sac.

In THE LANCET of March 18th, 1899, Mr. G. A. Wright and $\mathrm{Mr}$. W. Coates have recorded a case where a cyst three times the size of the bladder opened by a small orifice near the mouth of the right ureter. There was no obstruction in the urethra or prostatic enlargement. The man was 38 years of age and died from cystitis and urinary fever. A specimen (No. 3668A) is in the Museum of the Royal College of Surgeons of England taken from a man, aged 75 years. The bladder filled the pelvis and to the right was an oval sacculus communicating with the bladder by a small round aperture one and a half inches to the outer side of the right ureteral orifice. A drawing of a case is given in Coates's "Manual of Pathology." Wulff of Hamburg in 1904 operated upon a congenital diverticulum but I cannot conceive that any operation for removal of the diverticulum could have been undertaken in the case related with any hope of success.

Carlisle.

\section{A CASE OF INTRANASAL CHANCRE SIMULATING NASAL DIPHTHERIA.}

BY J. D. ROLLESTON, M.A., M.D. Oxon.,

ASSISTANT MEDICAL OFFICER AT THE GROVE FEVER HOSPITAL OF THE METROPOLITAN ASYLUMS BOARD.

A MARRIED man, aged 28 years, was admitted to hospital on March 7th, 1906, certified to be suffering from nasal diphtheria. On the medical certificate it was stated that diphtheria bacilli had been found in the colture. There was a previous history of diphtheria 14 years ago. For the last month his nose had been sore but it was not until it began to swell that he sought medical advice. On admission the lower two-thirds of the organ presented a most unsightly appearance, being considerably swollen and of a dusky-red colour. The right ala nasi, which was thickened and very tender, was lined on its inner surface by a membranous deposit from which on pressure a sanious discharge exuded. There was no excoriation of the philtrum such as is usually present in severe cases of nasal diphtheria. The left submaxillary and sterno-mastoid glands were considerably swollen and slightly tender. The buccal mucosa and fauces were normal. On the chest and abdomen a polymorphic eruption was present which from the absence of pruritus had hitherto escaped his attention. The nasal obstruction. causing frequent sniffing and use of the handkerchief, severe right frontal headache, and the consciousness of his deformity, all combined to render his condition one of considerable distress, though not of gravity. The temperature on admission was $99 \cdot 2^{\circ} \mathrm{F}$. but became normal the same evening and remained so till his discharge. A smear preparation and three successive cultures of the nasal membrane showed no diphtheria bacilli. A similar examination of the throat was also negative. The headache and partial impediment to respiration caused him to pass a restless night. During sleep it was noted that he lay with his mouth open and

2 A Text-book of Surgery (translated by Tilton and Stimson, 1900). Text-book on Pathology. snored. The following morning there was no improvement Though no history of direct or mediate exposure to venereal infection could be obtained the adenopathy and polymorphic eruption suggested the diagnosis of intranasal chancre. Mercury with chalk (two grains three times a day) were therefore administered and the nostril was swabbed frequently with black wash. The beneficial effects soon became apparent. On the 10th the nose, though still tender, was less swollen and red and showed a branny desquamation over the inflamed area. The headache had gone. The voice, hitherto nasal, soon became clear. The deposit within the nostril now consisted of dried-up crusts which gradually separated, revealing beneath a slightly raised granular swelling which resembled in its appearance and induration the primary lesion found in more usual situations. In the course of the next ten days the outer surface of the nose gradually regained its normal appearance and the intranasal swelling diminished in size. The glandular affection subsided more slowly but soon lost its tenderness. Beyond slight epistaxis which followed blowing the nose on the 13th, nothing further of note occurred and the patient was discharged on March 22nd.

In striking contrast to tertiary lesions of the nose intranasal chancres are so rare that Garel in 1900 had been able to find only 45 cases on record, six of which he bad seen himself. ${ }^{1}$ A search through subsequent literature has enabled me to add 14 more, ${ }^{2}$ which thus constitute a total of 60 cases, including the present one. The etiology of this localisation of the primary lesion is in Fournier's words, as a rule, impenetrable and mysterious. In only two could a history of direct or naso-genital contagion be obtained. ${ }^{3}$ Infection by the conveyance of the syphilitic virus to the nostril by the finger-nail is more common, either in consequence of venereal manipulations, or more frequently in syphilis insontium. Eight such cases were examples of professional chancres, four occurring in medical men ${ }^{ \pm}$and four in nurses.; Inanimate objects may sometimes convey infection. Thus in Higguet's case a snuff-box ${ }^{6}$ and in one of Collinet's cases a pencil were alleged to have been the infecting agents. Pre-existing lesions of the nasal mucous membrane were present in some cases. Thus Freudenthal's patient suffered from atrophic rhinitis, Chapuis's patient ${ }^{7}$ had impetigo of the nostril, and in Jullien's ${ }^{8}$ case there had been a recent severe injury to the nose. In the cases of Brunon and Gaetano picking of the nostril was an inveterate habit. In the majority of cases, however, among which my own patient is to be classed, no such history could be obtained. The diphtheroidal character of the lesion in the present case is of interest in that, though found in some of the other cases, ${ }^{\circ}$ in none of those hitherto published was the case regarded as diphtheria. Chancre of the tonsil, on the other hand, a much commoner extra-genital lesion, has occasionally been mistaken for diphtheria. In one such case organisms morphologically indistinguishable from Klebs. Löffler bacilli were isolated but were found to be nonpathogenic to guinea-pigs. ${ }^{10}$ It is probable that the bacilli found prior to my own patient's admission were of this class. It has been pointed out by Fournier that the membrane sometimes present on chancres can be distinguished from that of diphtheria by its strict localisation and by absence of any tendency to spread and invade neighbouring structures.

In the great majority of recorded cases the lesion was situated close to the orifice of the nostril and, as in my case,

1 Lyon Médical, 1900, p. 469

2 Brunon: Journal des Maladies Cutanées, 1904, p. 187. Calamida: Quoted in Centralblatt für Laryngologie, 1904, p. 125. Campbell Journal of American Medical Association, May 5th, 1906, p. 1352. Collinet: Annales des Maladies de l'Oreille, 1901, vol. ii., p. 93 (two cases). David: La Svphilis Fevrier, 1905. Freudenthal: New York Medical Journal, 1901, vol. i., p. 805. Gaetano: Gazzetta degli Ospedali, 1904, p. 847. Gaucher et Boisseau : Archives Raryngologie Medecine, 1906, p. 825, Gelle : Centralblatt fur Hunt: Liverpool inedico-Chirurgical Journal, 1906, p. 124. Lutati : Giornale Italiano delle Malattie Veneree, 1903, p. 151. Parker : THE LANCET. Jan. 26th. 1901, p. 238.

3IIulst: Quoted by Le Bart, Thèse de Paris, 1894. D'Aulnay: Annales de Dermatologie, 1895, p. 989.

4 Fournier: Les Chancres Fxtra-génitaux, 1897 (two cases). Campbell : loc, cit. Freudenthal : loc. cit.

5 Spencer Watson : Medical Times and Gazette, 1881, vol. 1., p. 428. Calamida, Garel, Gellé : lot. cit.

Gazette des Quoted by Le Bart, loc. cit. Hôpitaux, 1894, pp. 777 et seq, pp. 1103 et seq.

8 Quoted by Fournier, loc. cit

9 Lermoyez: Annales des Maladies de l'Oreille, 1892, Part 2. p. 517. Thibierge: Gazette Hebdomadaire, 1894, p. 198. Moure: Revue de Laryngologie, 1892, p. 461. IRueda: Ibid., 1895, p. 157 
could be seen without the aid of a speculum. The reason assigned for this situation is that it is the part within reach of the finger which, as stated above, is the usual carrier of infection. In most of the cases the lesion has been situated on the septum. In Mendel's ${ }^{11}$ case a symmetrical chancre occupied each aspect of the septum. The present case is thus exceptional and resembles that of Spencer Watson. The erysipelatous condition of the external nostril, so marked a feature in my case, was present in those reported by Thibierge, ${ }^{12}$ Chapuis, Jacobi, ${ }^{13}$ Parker, and David. It is due, as Thibierge points out, to a secondary infection. Chancres on the genitals occasionally, though not so frequently as extragenital chancres, are liable to the same complication. Tenderness of the glands, which is usually absent in syphilitic adenopathy, is due to the same cause. Tenderness of the enlarged glands was a special feature in the cases of Rueda, Bieck, ${ }^{1.1}$ and Collinet. In Rueda's case suppuration of the submaxillary glands actually occurred. Affection of the nasal duct may produce lacrymation, as in Campbell's and Gaucher's cases, or even lead to a lacrymal abscess, as in Nettleship's ${ }^{1 \overline{0}}$ patient.

The symptoms, so prominent in my patient, may be ill marked, as in Marfan's ${ }^{16}$ and Brunon's cases. In one of Garel's ${ }^{17}$ cases the intranasal phenomena were so slight and the glandular enlargement so obtrusive that the patient thought she was suffering from mumps. It is exceptional for constitutional disturbances to occur, as in Spencer Watson's case, where high fever and great mental prostration were noted. In Freudenthal's and Campbell's cases the general symptoms were so predominant that the disease was first regarded as influenza. Many of the recorded cases resemble the present one in the co-existence of the primary and secondary lesions when the patient was first seen, so that a correct diagnosis was soon made, but in others the true nature of the lesion was not recognised till the appearance of the roseola some days or weeks later. In Lermoyez's ${ }^{18}$ case the lesion was first mistaken for sarcoma, but the subsequent development of a typical roseola led to a correct diagnosis. In this connexion it may be said that the early involvement of the glands and the slight degree of epistaxis indicate syphilis rather than a malignant growth. In a few instances the chancre was regarded as a tertiary lesion till the secondary eruption developed. In the present case the diagnosis was established by the characteristic induration of the lesion, the enlargement of the submaxillary glands, the co-existence of the syphilitic eruption, and the rapidly beneficial effect of mercury. The ubiquity of syphilis combined with the prevalence of picking the nose makes it surprising that intranasal chancres are so rare. There can be little doubt that several cases pass unrecognised. In conclusion it may be said that the existence of a chancre in such an unusual situation is of interest not only from the standpoint of syphilography and rhinology but also from that of internal medicine inasmuch as the latent or misleading character of the initial lesion may throw light on the etiology of subsequent affections, notably tabes and general paralysis.

I am indebted to Dr. J. E. Beggs, medical superintendent of the Grove Hospital, for permission to publish this case.

Tooting.

\section{EXAMINATION OF THE FACES. BY DR. ROBERT BAUMSTARK.}

THE examination of intestinal ejections is still a dificulty to the practitioner. It is a well-known fact that the important progress made in the last 20 years in the knowledge of the functions of the stomach is due to the Ewald "test breakfast" and the Riegel "test meals" which are recognised as trustworthy methods. A direct examination of the intestine is much more difficult. Up to now the only means of becoming acquainted with the functional efficiency of the intestine has been by means of testing in the

11 Annales de Dermatologie, 1895, p. 210. 13 Dermatologische Zeitschrift, 1897 . 198.

1* Berliner Klinische Wochenschrift, 1897, p. 1078

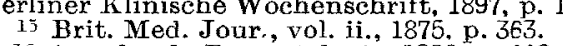

16 Annales de Dermatologie, 1890, p. 449

17 Garel: D'Aulnay, loc. cit.; Kohn: New York Medical Journal, 1897, p. 421 .

28. Moure, Revue de Laryngologie, 1887, p. 385, and Garel, loc. laboratory. But there are many objections to this method: First, it is complicated and needs too many appliances and thus is useless to the practitioner; further, the residues in the fæces result not only from the food taken but also from the intestinal, liver, and pancreatic secretions, and from intestinal bacteria, which are all liable to individual changes.

To try to form an opinion of the capabilities of the intestine by means of examination of the fæces with daily changing food is impossible, for even in healtby individuals there are manifold nutritious elements which are not made use of and which are ejected in varying quantities in the fæces. A special diet must be adhered to and must fulfil the following conditions: 1 . It must contain the necessary amount of calories and suitable proportions of the three chief groups of food-stuffs. 2. It must be digestible, taken readily, and agree well, in order that it can even be assimilated by a disordered intestine. 3. Coarse macroscopical remnants must not appear in the frces. At the same time the consistency of the frces must not be so fine as to lack the power of stimulating the bowel. 4. It must be easily obtained in any household. These conditions have at last been fulfilled after many years of experiment in a diet devised by Adolph Schmidt. This diet is as follows :-

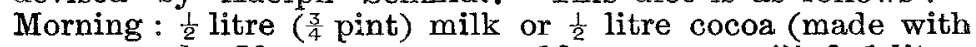
cocoa powder 20 grammes, sugar 10 grammes, milk 0.1 litre, rest 0.4 litre water) and 50 grammes rusk. Before noon : $\frac{1}{2}$ litre gruel (made with 40 grammes groats, 10 grammes butter, 200 grammes milk, one egg, and 300 grammes water). Noon: 125 grammes minced beef lightly fried (so as to be raw inside) in 20 grammes butter, 190 grammes potatoes mashed with 100 grammes milk, and 10 grammes butter. Afternoon: The same as in the morning. Evening: The same as in the forenoon. Altogether the diet consists of $1 \frac{1}{2}$ litres milk, 100 grammes rusk, two eggs, 50 grammes butter, 125 grammes minced beef, 190 grammes potatoes, and 80 grammes oatmeal. This total represents 2234 calories.

In the greater number of cases, especially in the generality of slighter intestinal troubles, there is no difficulty with this diet. In some cases, however, especially in more serious cases, troubles may arise in the form of diarrhoea or constipation; or perhaps the patient cannot satisfy his appetite with this diet; or, again, he may not be able thoroughly to assimilate the diet. It is possible to remedy this latter difficulty by lessening or increasing the quantity of milk. Diarrhoea and constipation often disappear if one continues the diet four or five days instead of three. Diarrhoea often also passes off if instead of giving $1 \frac{1}{2}$ litres of milk alone one prescribes less, and in combination with cocoa, gruel, and mashed potatoes, or with the addition of brandy, barley water, or salicylate of soda $(0.3$ gramme in the daily quantity of $1 \frac{1}{2}$ litres.)

The quantity of meat may, if necessary, be a little reduced. It is hereby seen that alterations can be made to a moderately wide extent so as to adjust the diet to each individual. Again, the principal meal of meat and potatoes may be given in the evening instead of at noon. Toast can also be given instead of rusks. It should, however, be borme in mind that the preparation of the meat must be according to the above method-that is, raw in the centreand there must also be the necessary quantity of carbohydrates. It is therefore not possible according to Schmidt to increase either the quantity of the meat or of the carbohydrates, for that amount has been chosen so that it may be entirely assimilated by the intestine. Schmidt therefore persists with milk, in spite of digestive difficulties. However, according to his calculations in from 5 to 8 per cent. of cases, the end is not attained owing to the irritation caused by the milk.

It has not yet been ascertained why this is so; possibly the sugar of milk is the cause (on account of its great osmotic and aperient properties) as lactic acid fermentation occurs easily and thus causes irritation of the mucons membrane of the intestine. It may be due also to the special conditions produced by the bacterial flora on the milk, so that numerous quantities of aperient toxins are formed. I myself now aim at using less pure milk for the test diet and being guided as much as possible by individual circumstances. When I learn that milk bas not formerly agreed with the patient and that in spite of a prescribed milk cure relapses have occurred, I then at the outset reduce to a minimum the quantity of milk used with the gruel, cocoa, and potatoes, and under these conditions cases of disturbance are indeed exceedingly rare.

It is wise to examine the stools carefully before the test 